\title{
ENFERMEIROS E O MERCOSUL: REGULAMENTAÇÃO E CONTROLE DO EXERCÍCIO PROFISSIONAL
}

ENFERMEROS Y EL MERCOSUR, REGLAMENTACIÓN Y CONTROL DEL EJERCICIO PROFESIONAL.

THE NURSES AND THE MERCOSUL. REGULATION AND CONTROL OF THE PROFESSIONAL PRACTICE

\section{Ana Luiza Stiebler Vieira ${ }^{1}$}

RESUMO: Estudo comparado da regulamentação e controle do exercício profissional dos enfermeiros no Brasil, Argentina, Uruguai e Paraguai, delineando suas especificidades, diferenças e semelhanças, na perspectiva de implantação do Mercado Comum do Cone Sul, o qual pressupōe a livre circulação de trabalhadores nos mercados de trabalho dos paises-membros do Tratado de Assunção.

UNITERMOS: Enfermeiros - Mercosul - Regulamentação profissional - Controle profissional.

ABSTRACT: A study comparing the regulation and control of the professional pratice of nurses in Brasil, Argentina, Uruguai and Paraguay, delineating their particularities, differences and similarities in the perspective of the implementation of the Cone Sul Common Market, which presupposes the free circulation of workers in the workplaces of the member-countries of the Asuncion Treaty.

KEYWORDS: Nurses - Mercosul - Regulation professional - Control professional pratice.

RESUMEN: Estudio comparado de la reglamentación y control del ejercicio profesional de los enfermeros en Brasil, Argentina, Uruguay y Paraguay, delineando sus especificidades, diferencias y semejanzas, en la perspectiva de implantación del Mercado Común del Cono-sur, el cual presupone la libre circulación de trabajadores en los mercados de trabajo de los paises miembros del Tratado de Asunción.

UNITÉRMINOS: Enfermeros - Mercosur - Reglamentación profesional - Control profesional.

1 Doutora em Enfermagem, Pesquisadora Associada da Escola Nacional de Saúde Pública Fiocruz, Professora Assistente da Faculdade de Enfermagem da UERJ.

R. Bras. Enferm. Brasília, v. 51, n. 1, p. 123-138, jan./mar., 1998 


\section{O MERCOSUL E OS ENFERMEIROS}

O Mercosul - Mercado Comum do Cone Sul - representa a proposta de integração latino-americana do Cone Sul no contexto da década de 90 que se caracteriza pela transnacionalização político-econômica mundial, com a formação de blocos regionais. Como o objetivo final do acordo é o mercado comum a partir do ano 2006, esta forma de integração implica na livre circulação de bens, serviços e fatores produtivos - incluídos aí a livre circulação de trabalhadores - entre os quatro países-membros: o Brasil, a Argentina, o Uruguai e o Paraguai.

Levando em consideração que a migração de recursos humanos qualificados pode significar uma perda social e econômica importante para os países de origem (independentemente do país de destino), o livre trânsito dos enfermeiros constitui atualmente, um tema importante para reflexão e análise. Implica, na prática, enfrentar questões tais como: as políticas de migração; formação e utilização dos enfermeiros (e suas repercussões no sistema formador e prestador dos serviços de saúde); a equiparação curricular; e a regulamentação e o controle profissional.

Acreditando na descentralização das reflexões sobre $\circ$ processo de mobilidade profissional dos enfermeiros no Mercosul, objetivamos contribuir com as diversas instituições representativas da enfermagem brasileira, em especial as dos enfermeiros, apresentando a atual realidade no Cone Sul da regulamentação e do controle do exercício profissional dos enfermeiros. O presente trabalho é um recorte de uma pesquisa mais ampla, de doutorado, onde analisamos ainda a formação e o mercado de trabalho dos enfermeiros no Brasil, Argentina, Uruguai e Paraguai, discutindo as perspectivas de migração profissional dos enfermeiros nos seus mercados de trabalho em saúde.

\section{REGULAMENTAÇÃO E CONTROLE DO EXERCíCIO PROFISSIONAL}

O Brasil, diferentemente dos demais países-membros do Mercosul, é o único país que conta com um órgão específico de enfermagem para o controle do exercício profissional de suas categorias, função exercida na Argentina, Uruguai e Paraguai pelos respectivos Ministérios da Saúde. Apenas o Brasil e a Argentina dispõem de legislação do exercício profissional, encontrando-se os projetos de lei do Uruguai e Paraguai ainda em tramitação nos Congressos Nacionais.

Embora historicamente seja recente a criação, no Brasil, do Conselho Federal de Enfermagem ${ }^{2}$ - COFEN - e dos Conselhos Regionais (em 12/07/73 através da Lei $\mathrm{N}^{\circ} 5.905$, mas com instalação definitiva em 05/03/75 quando foi

\footnotetext{
${ }^{2}$ Criado como Autarquia Federal mas, em 1996, transformado em Empresa Pública ( assim como todos os Conselhos de profissionais ) por força das Medidas Provisórias $\mathrm{N}^{\circ} 1.549-35$ e N¹.54936, publicadas no Diário Oficial da União em 09 de outubro e 07 de novembro de 1997.
} 
publicada a Portaria $\mathrm{N}^{\circ} 3.059$, do Ministério do Trabalho), atualmente, esta entidade concentra grande poder decisório relativo ao exercício profissional da enfermagem brasileira. $\mathrm{O}$ documento expedido pelos Conselhos Regionais (além do certificado de conclusão de curso) constitui a credencial reconhecida pelas instituições de saúde e de ensino no país para a ocupação de postos de trabalho, documento indispensável em concursos ou processos de seleção para empregos ou cursos de pós-graduação lato sensu.

A lei vigente no Brasil, que regulamenta o exercício profissional das categorias de enfermagem, data de 1986 , sob $\circ \mathrm{N}^{\circ} 7.498$, com regulamentação do Presidente da República através do Decreto №94.406, de 08 de junho de 1987. Reconhece como categorias de enfermagem ${ }^{3}$ os enfermeiros, os técnicos ${ }^{4}$, os auxiliares de enfermagem ${ }^{5}$ e as parteiras ${ }^{6}$. Os enfermeiros são considerados os titulares do diploma de graduação, do diploma ou certificado de obstetriz, enfermeira obstétrica, ou de títulos equivalentes conferidos por escolas estrangeiras, registrados em virtude de intercâmbio cultural ou revalidados no Brasil como diploma de enfermeiro (COFEN, 1990:23). Legalmente, aos enfermeiros cabe em caráter exclusivo entre as categorias de enfermagem (COFEN, 1990:25-26):

- a direção do órgão de enfermagem integrante da estrutura básica da instituição de saúde, pública ou privada, e chefia de serviço e de unidade de enfermagem;

- organização e direção dos serviços de enfermagem e de suas atividades

${ }^{3}$ Os atendentes de enfermagem, embora não reconhecidos pelo COFEN por não deterem formação formal, são uma categoria na equipe de enfermagem brasileira que, ainda em 1992, representava $13,8 \%$ do total da força de trabalho de enfermagem ou respectivamente ocupantes de 142.356 postos de trabalho em saúde no país (IBGE, 1992:85-89). Legalmente, a partir de 1994, de acordo com a Lei $N^{\circ} 8.967$ do COFEN, foi assegurado aos atendentes, admitidos nos serviços de saúde antes da vigência da lei do exercício profissional (08/06/87), o exercício de atividades elementares de enfermagem sob orientaçăo e supervisão do enfermeiro. Sob a denominação genérica de atendentes, fazem parte pessoas contratadas com diversos nomes de acordo com as instituiçōes de saúde: atendente de enfermagem, auxiliar de serviços médicos, auxiliar operacional de serviços diversos, auxiliar hospitalar, visitador sanitário, atendente de saúde rural, instrumentador cirúrgico, agente de saúde e auxiliar de saúde.

${ }^{4}$ Titulares do respectivo diploma expedido por escolas brasileiras ou estrangeiras registrado em virtude de intercâmbio cultural ou revalidado no Brasil como diploma de Técnico de Enfermagem (COFEN, 1990:24). Em 1994, segundo o COFEN (1994:1), totalizavam 50.261 no país.

${ }^{5}$ Titulares do respectivo diploma ou equivalente de acordo com a Lei $\mathrm{N}^{\circ} 2.822$ de 1956 e a Lei №2.604 de 1955 (com certificado espedido até 1961); do certificado de enfermeiro prático ou prático de enfermagem expedido até 1964 pelo Serviço Nacional de Fiscalização de Medicina e Farmácia do Ministério da Saúde; pessoal enquadrado como auxiliar de enfermagem através do Decreto-Lei №299 de 1967; e ainda os titulares do diploma ou certificado conferido por escolas ou cursos estrangeiros, registrado em virtude de intercâmbio cultural ou revalidado no Brasil como auxiliar de enfermagem (COFEN, 1990:24). Em 1994, segundo o Cofen (1994:1), totalizavam 197.192 no país.

${ }^{6}$ Titulares do certificado previsto no Decreto-Lei $N^{\circ} 8.778$ de 1946; do certificado de parteiro ou equivalente, conferido por escolas ou cursos estrangeiros, registrado em virtude de intercâmbio cultural ou revalidado no Brasil até 26/06/88, como certificado de parteiro ( COFEN, 1990:24).

R. Bras. Enferm. Brasília, v. 51, n. 1, p. 123-138, jan./mar., 1998 
técnicas e auxiliares nas empresas prestadoras desses serviços;

- planejamento, organização, coordenação, execução e avaliação dos serviços da assistência de enfermagem;

- consultoria, auditoria e emissão de parecer sobre matéria de enfermagem;

- consulta de enfermagem;

- prescrição da assistência de enfermagem;

- cuidados de enfermagem de maior complexidade técnica e que exijam conhecimentos científicos adequados e capacidade de tomar decisões imediatas.

Cabe também aos enfermeiros, como integrantes da equipe de saúde, as atribuições de:

- participação no planejamento, execução e avaliação da programação de saúde e dos planos assistenciais de saúde;

- prescrição de medicamentos previamente estabelecidos em programas de saúde pública e em rotina aprovada pela instituição de saúde;

- participação em projetos de construção ou reforma de unidades de internação;

- prevenção e controle sistemático da infecção hospitalar, inclusive como membro das respectivas comissões;

- participação na elaboração de medidas de prevenção e controle sistemático de danos que possam ser causados aos pacientes durante a assistência de enfermagem;

- participação na prevenção e controle das doenças transmissíveis em geral e nos programas de vigilância epidemiológica;

- prestação de assistência de enfermagem à gestante, parturiente, puérpera e recém-nascido;

- participação nos programas e nas atividades de assistência integral à saúde do individual e de grupos específicos, particularmente daqueles prioritários e de alto risco;

- acompanhamento da evolução e do trabalho de parto;

- execução e assistência obstétrica em situação de emergência e execução do parto sem distocia;

- participação em programas e atividades de educação sanitária, visando à melhoria de saúde do indivíduo, da família e da população em geral;

- participação nos programas de treinamento e aprimoramento de pessoal de saúde, particularmente nos programas de educação continuada;

- participação nos programas de higiene e segurança do trabalho e de prevenção de acidentes e de doenças profissionais do trabalho;

- participação na elaboração e na operacionalização do sistema de referencia e contra-referência do paciente nos diferentes niveis de atenção à saúde;

- participação no desenvolvimento de tecnologia apropriada à assistência de saúde;

- participação em bancas examinadoras, em matérias específicas de enfermagem, nos concursos para provimento de cargo ou contratação de 
enfermeiro ou pessoal técnico e auxiliar de enfermagem.

$\mathrm{E}$ ainda aos profissionais titulares de diploma ou certificado de obstetriz ou enfermeira obstétrica, além das atividades do enfermeiro como integrante da equipe de saúde, cabe-lhes legalmente (COFEN, 1990:26):

- prestação de assistência à parturiente e ao parto normal;

- identificação de distocias obstétricas e tomada de providências até a chegada do médico;

- realização de epsiotomia e epsiorrafia, com aplicação de anestesia local, quando necessária.

$\mathrm{Na}$ Argentina, tanto a regulamentação quanto o controle do exercício profissional da enfermagem são atribuições ainda centralizadas no Ministério da Saúde e Ação Social, fato que ocorre também em todas as profissões de saúde. Nem mesmo aos médicos é outorgada a autonomia para estas atribuições. Através dos diplomas expedidos pelas faculdades, o registro profissional é outorgado no âmbito da capital federal, pela "Dirección Nacional de Control del Ejercicio Profesional" do Ministério da Saúde e Açäo Social e, no restante do pais, pelos órgãos das jurisdições subordinados a este Ministério (Abramzón, 1995:70). No entanto, de acordo com Muñoz et. al. (1995:66), estes órgãos, na maioria das províncias, se limitam à outorga do registro profissional, caracterizando no pais a ausência do controle do exercício profissional das categorias de enfermagem.

A única associação nacional de enfermagem existente na Argentina é a "Federación Argentina de Enfermeria" (FAE), criada em 1968, com sede em Buenos Aires, de caráter técnico-científico (responsável também pela ética e deontologia profissional), que congrega apenas os enfermeiros. Ao nivel dos estados, os enfermeiros contam ainda com 22 "Asociaciones Provinciais de Enfermeria" que também se dedicam aos aspectos técnico-científicos dos licenciados e dos enfermeiros, além de uma "Asociación de Escuelas Universitarias e uma Asociación de Escuelas Terciárias" (Muñoz et al. 1995:58).

O corpo normativo que regula o exercício das atividades profissionais da enfermagem era estruturado na Lei $N^{\circ} 17.132 / 67$ (vigente até hoje para as categorias de saúde que ainda não tiveram aprovadas as sua leis específicas do exercício profissional). Em 23/10/91, através da promulgação da Lei $\mathrm{N}^{\circ} 24.004$, a enfermagem passou a contar com sua legislação especifica, a qual, mesmo

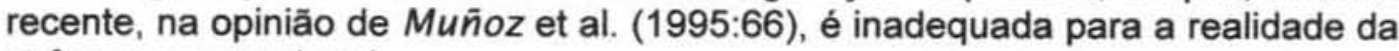
enfermagem nacional. 
De acordo com esta Lei (Presidencia de la Republica, 1991:1-11), se reconhece no país para o exercício da enfermagem apenas o "profesional" ${ }^{\prime \prime}$, que são os licenciados, os enfermeiros e os auxiliares de enfermagem ${ }^{8}$. Os "profesionales" são considerados os titulares dos diplomas ou certificados de licenciatura e de enfermeiro outorgado pelas escolas de enfermagem nacionais, provinciais, municipais e privadas reconhecidas; ou os titulares de certificado equivalente, expedido por países estrangeiros, revalidado de acordo com a legislação vigente e os convênios de reciprocidade.

Aos licenciados, além das atribuições dos enfermeiros, cabe-lhes legalmente em caráter de exclusividade, a docência, a assessoria em enfermagem e a administração de serviços de enfermagem. Embora na prática, segundo Muñoz et al. (1995:52), devido à insuficiência quantitativa dos licenciados, essas atribuições são comumente assumidas pelos enfermeiros. Para estes últimos, excluídas a docência, a assessoria em enfermagem e a administração dos serviços de enfermagem, a lei do exercício profissional (Presidencia de la Republica, 1991:3-4) outorga as atribuições de:

- planejar, implementar, executar, supervisionar e avaliar a assistência de enfermagem na prevenção, recuperação e reabilitação da saúde;

- prestar cuidados de enfermagem a pessoas com problemas de saúde de maior complexidade;

- realizar consultas de enfermagem e a prescrição de enfermagem;

- organizar e controlar o sistema de informações e registros pertinentes à enfermagem;

- estabelecer normas de previsão e controle de materiais e equipamentos para assistência de enfermagem;

- planejar, implementar e avaliar programas de saúde juntamente com a equipe interdisciplinar nos níveis nacional e local;

- participar na programação das atividades de educação sanitária;

- participar nos programas de higiene e segurança do trabalho na prevenção de acidentes de trabalho e doenças profissionais;

- participar no desenvolvimento de tecnologia apropriada para a saúde;

- realizar/participar em investigações sobre temas de enfermagem e de saúde;

- realizar todos os cuidados de enfermagem para satisfazer as necessidades das pessoas nas distintas etapas do ciclo vital.

${ }^{7}$ Os atendentes de enfermagem, apesar de também não serem reconhecidos legalmente como categoria de enfermagem na Argentina (mais conhecidos por empíricos), representavam, em $1994,11,8 \%$ (ou 10.000 atendentes) do total da força de trabalho de enfermagem no país (OPS/MSyASN/SS, 1994:32). E assim, como no Brasil, os atendentes argentinos, segundo Muñoz et al. ( 1995:53 ), têm sido clientela prioritária de projetos de escolarização e de profissionalização.

${ }^{8}$ Titular do certificado de auxiliar de enfermagem outorgado por instituições nacionais, provinciais, municipais e privadas, reconhecido pelo Ministério da Saúde e Ação Social; ou titular de certificado equivalente outorgado por paises estrangeiros que deve ser revalidado (Presidencia de la Republica, 1991:3). Em 1994, de acordo com Muñoz et al. (1995:34), totalizavam 49.000 auxiliares no país. 
De acordo ainda com a legislação vigente, aos licenciados e enfermeıros é reservado também em caráter exclusivo o exercício profissional e autônomo em instituições públicas e privadas, nos domicílios e em consultórios particulares. A legislação incumbe-lhes ainda, as responsabilidades de controle do registro da autorização profissional no Ministério da Saúde, de todos os recursos humanos de enfermagem que trabalham sob as suas coordenações; de denunciar acidentes de trabalho com caráter de delito; de notificar doenças ou quaisquer circunstâncias que comprometam a saúde da população; e ainda de adotar medidas exigidas legalmente para controlar as condições de higiene e limpeza nas instituições de saúde.

No Uruguai, para que o enfermeiro - como também qualquer profissional de saúde - possa exercer sua profissão, é necessário que o título obtido no país seja registrado no Ministério de Saúde Pública através do Departamento de Coordenação e Controle, que outorga uma carteira de habilitação profissional. Obrigatoriamente também se faz o registro na "Caja de Jubilaciones y Pensiones Profesionales". O enfermeiro estrangeiro tem seu título examinado pelo "Instituto Nacional de Enfermería" que o revalida ou indica e fornece a complementação dos estudos para equiparação curricular. Uma vez revalidado o título, o profissional deverá fazer os mesmos registros, sendo que o direito ao emprego público só será concedido mediante comprovada cidadania uruguaia, não necessária nas instituições privadas de saúde (Rígole et al. 1995:124; Campos et al. 1995:42). Para a obtenção da cidadania segundo a Constituição vigente (de 1967, com reformas de 1989 e 1994), é necessário que o indivíduo com família constituída tenha residência habitual de três anos no país, ou solteiros com residência habitual de cinco anos ou ainda obtenha permissão especial da Assembléia Geral por serviços notáveis ou méritos relevantes. O Art. 76 prevê que, somente após três anos, a pessoa com cidadania legalizada poderá ser chamada nos empregos públicos e ainda, veda a cidadania para o desempenho de funções de professor no ensino superior do país (Republica Oriental del Uruguai, 1967:16-17).

A centralização da outorga do exercício profissional no Ministério de Saúde Pública data de 1934 com a Lei Orgânica ํㅜ 9.202, que criou o próprio Ministério e previu uma "Comisión Honorária de Salud" responsável no país até hoje pelo controle deontológico e do exercício dos profissionais de saúde (Rígole, et. al. 1995:124). De acordo com esta Lei, no seu Capítulo VI, a Comissão de Saúde Pública é presidida pelo Ministro da Saúde e constituída por mais quinze membros designados pelo Poder Executivo (aplicando-se a proporcionalidade fixada para a participação de membros dos serviços descentralizados), com atribuições, além de constituir um tribunal disciplinar para profissionais de saúde, de amplos poderes referentes a todas as questões técnicas e administrativas relacionadas com a assistência e higiene pública do país (Republica Oriental del Uruguay, 1934:4-5). 
O MSP reconhece como categorias de enfermagem ${ }^{9}$ os enfermeiros e os auxiliares de enfermagem ${ }^{10}$. Para o devido registro e controle do exercício profissional, o MSP reconhece como enfermeiro aquela pessoa que se graduou como "Licenciado en Enfermería" no "Instituto Nacional de Enfermería"; como "Licenciada" ou "Nurse" da "Escuela de Nurses Dr Carlos Nery", do MSP. Reconhece ainda, apesar das discordância do "Colegio de Enfermeras del Uruguay" (devido as disparidade do currículo), os trinta e um egressos da "Escuela de Salud Dr. José Scosería" do MSP, ou seja, as "Nurses Licenciadas en Enfermeria" (Pitamiglio, 1995:34). De acordo com o regime jurídico dos profissionais de saúde, o nível superior de enfermagem recebe várias denominações equivalentes: Enfermeiro, Nurse, "Licenciado en Enfermería" e "Nurse Licenciado en Enfermería" (Pitamiglio, 1995:139-141). Para distinguir o nível superior de enfermagem, o "Colegio de Enfermería" como o "Instituto Nacional de Enfermería del Uruguay" utilizam a denominação "Enfermería Profesional" (Instituto Nacional de Enfermería; Colegio de Enfermeras del Uruguay, 1995:9).

A criação de um Colegiado, de uma lei de exercício profissional, bem como o controle profissional pelas categorias de saúde, segundo Rígole et al. (1995:124), constituem antiga aspiração no país. Até hoje, os médicos não conseguiram a criação do seu Colegio e a sua lei do exercício profissional, projetos que tramitam desde 1988 no Parlamento Nacional. Os enfermeiros por sua vez conseguiram a aprovação Parlamentar, em 1992, do "Colegio de Enfermeras del Uruguay" para o qual, tiveram auxílio decisivo do Conselho Internacional de Enfermagem, da Federação Pan-americana de Profissionais de Enfermagem e da Organização Internacional do Trabalho ${ }^{11}$. Porém, o projeto de lei do exercício profissional da enfermagem no país (para substituir o obsoleto "Regulamento de Nurses", de março de 1934) encontra-se, desde 1991, em tramitação no Parlamento Nacional. Tal projeto foi inicialmente elaborado pelo "Comité Nacional de Legislación de Enfermería" ou CONADELE (integrado por licenciados e auxiliares de enfermagem), posteriormente analisado em diferentes regiões do país e aprovado em um encontro nacional de enfermagem em 1990 e revisado, em maio de 1995, pelo "Colegio de Enfermeras del Uruguay" (Colegio de Enfermeras del Uruguay, 1995:1).

De 1994 a 1992, os enfermeiros eram representados pela "Asociación de Nurses Del Uruguay" mas, com a aprovação Parlamentar em 1992 do Colegiado, atualmente o "Colegio de Enfermeras del Uruguay" (CEDU) constitui a única organização de representação corporativa (exclusiva dos enfermeiros)

${ }^{9}$ Os "empíricos", ou os atendentes de enfermagem, também não são reconhecidos legalmente no Uruguai como categoria profissional apesar de totalizarem, em 1994, segundo Clemente (1994:12), 6.000 pessoas em todo o país.

${ }^{10}$ Titulares do certificado de auxiliar de enfermagem expedido pela "Escuela de Sanidad" do MSP ou de instituições privadas de ensino e reconhecido pelo MSP. Em 1994, totalizavam 17.000 no país (Clemente, 1994:6).

${ }^{11}$ Segundo relato da Secretária Geral do "Colegio de Enfermería", Sra. Ema Magnami, em 21/05/96. 
no país. Em maio de 1996, o CEDU contava com 1.000 enfermeiros filiados (55,5\% do total de 1.801 enfermeiros ativos), pagantes de uma quota mensal de quarenta e dois pesos (cinco dólares e meio). Com sede própria em Montevidéu (na verdade adquirida pela "Asociación de Nurses"), sustenta-se através das quotas mensais, mas principalmente através das rendas obtidas de eventos culturais (cursos, encontros, seminários e congressos). Comumente, o CEDU promove esses eventos em parceria com o "Instituto Nacional de Enfermería".

De acordo com o seu estatuto, o "Colégio de Enfermeras del Uruguay", tem como objetivos (Colegio de Enfermeras del Uruguay, 1992:1):

- Propiciar o desenvolvimento profissional de seus filiados;

- Assessorar e assistir seus filiados em assuntos gremiais (corporativos) e profissionais através de uma Comissão Gremial;

- Contribuir para elevar o nível de assistência dos serviços de enfermagem;

- Participar com as autoridades nacionais nas definições de políticas de saúde da população e da profissão;

- Realizar atividades entre os membros da própria profissão e interdisciplinar no âmbito nacional em assuntos de caráter científico ou corporativo;

- Realizar intercâmbio internacional da enfermagem profissional;

- Controlar a aplicação da legislação e do código de ética do enfermeiro em nível nacional.

Percebe-se através desses objetivos que o CEDU acumula duas atribuições de importância para a categoria, ou seja, a de desenvolvimento profissional (de caráter mais cultural), e a de controle do exercício profissional. Entretanto, como - Estado, através do MSP (em particular da Comissão de Saúde Pública), controla de fato e de direito o exercício de todos os profissionais de saúde no país, o CEDU não tem, na verdade, a autonomia desejada nesse aspecto profissional embora explicite-a no seu estatuto. Vale lembrar que o Colegio só dispõe até hoje de um "Regulamento de Nurses" de maio de 1934 (considerado obsoleto, já que não contempla as questões profissionais atuais) como também ainda não obteve a aprovação Parlamentar da lei do exercício profissional da enfermagem no Uruguai.

O "Proyecto de Ley Nacional de Enfermería", revisado em 1995, e cuja aprovação ainda é aguardada e aspirada pelo Colegio como instrumento legal de suporte para o controle do exercício profissional da enfermagem no país através deste órgão em substituição ao MSP, em seus sete artigos, define (Colegio de Enfermeras del Uruguay, 1995:1-3):

- como profissionais de enfermagem, os "Licenciados en Enfermería" com título expedido ou revalidado pela Universidade da República; e os "Assistentes de Enfermería" (ou os titulares do certificado de auxiliar de enfermagem expedido pelas instituições públicas de ensino). 
- como competências exclusivas do Licenciado, conduzir o processo de assistência de enfermagem; participar no processo de assistência e de ensino nos distintos ciclos vitais do indivíduo assumindo tarefas mais complexas; formular diagnóstico, tratamento e avaliação de enfermagem; assumir a responsabilidade do ensino em todos os níveis de formação; promover e participar de investigações nas áreas de sua competência; administrar serviços docentes e de assistência de enfermagem nas instituições públicas e privadas; exercer a direção das divisões e departamentos de enfermagem nas instituições públicas e privadas de assistência médica; avaliar a capacidade profissional do pessoal de enfermagem em concursos, provas de ingresso, admissão, promoção; realizar auditorias e consultorias em enfermagem; e dirigir e supervisionar as atribuições e o trabalho do assistente de enfermagem de complexidade técnica de acordo com a formação curricular;

- como integrante da equipe de saúde, ao Licenciado compete participar na determinação, execução e avaliação das políticas, planos e programas de saúde; na promoção, proteção da saúde e prevenção das doenças, enfatizando a atenção primária de saúde; na elaboração de projetos de construção e reformas de unidades de assistência de saúde; e participar na investigação na área da saúde.

- que os profissionais de enfermagem, na data de aprovação desta lei possuir o título de "Enfermera Universitaria" ou o certificado de "Auxiliar de Enfermería", deverão optar pelo título de "Licenciado en Enfermería" ou pelo certificado de "Assistente de Enfermería", respectivamente, dentro de um prazo de dois anos, cumprindo os requisitos e formalidades estabelecidas pela regulamentação desta lei.

No Paraguai, a primeira menção legal para o exercício da enfermagem e particularmente das obstetrizes data de 1936, através do Decreto-Lei número 2001, que, em seus Art.9 (Inc. 6) e Art.21 (Republica del Paraguay, 1936:3-4), encarregou o Ministério da Saúde Pública como regulamentador do exercício profissional do médico cirurgião, farmacêutico, odontólogo e obstetra, cujos títulos de habilitação outorgados ou reconhecidos pela Universidade Nacional seriam inscritos neste Ministério. Os praticantes de medicina, enfermeiras ${ }^{12}$, nurses, massagistas, ortopédicos, óticos e outros afins estariam isentos desta inscrição e suas atividades foram consideradas legais.

Somente em 1952 as enfermeiras passaram para o nível superior com a criação do primeiro curso de Licenciatura em Enfermagem e de Licenciatura em Obstetrícia no país, na Escola de Enfermagem do Instituto Andrés Barbero. Este Instituto foi incorporado à Universidade Nacional de Assunção em 1963, através do Decreto №29.107 (Republica del Paraguay, 1963:1-2), que o reconheceu como apto à formação universitária de enfermeiras, obstetrizes e assistentes sociais.

\footnotetext{
${ }^{12}$ No feminino, conforme mencionado no Decreto.
} 
Por sua vez, o Decreto N³5.094, de 1958 (República del Paraguay, 1958:12), estabeleceu como requisitos para exercer a profissão na qualidade de enfermeira as possuidoras de diplomas expedidos pelas escolas de enfermagem reconhecidas no país que seguissem um conjunto mínimo de exigências de acordo com as recomendações do Conselho Internacional de Enfermeiras; as diplomadas por escolas de enfermagem estrangeiras com títulos previamente revalidados; as Visitadoras de Higiene Polivalente $e$ as Visitadoras de Higiene Social, com títulos expedidos pelo MSPyBs; e as obstetrizes egressas da "Escuela de Visitadoras de Higiene Polivalente", com títulos expedidos pelo MSPyBS. Ao mesmo tempo, outorgou ao MSPyBS o registro profissional e a regulamentação do próprio Decreto.

Atualmente, a regulamentação em nível nacional do exercício profissional na área da saúde (inclusive dos técnicos e auxiliares) está enunciada no Código Sanitário. O Art.215, estabelece, como requisitos para o exercício das profissões em ciências da saúde, a titulação expedida pelas universidades do país, ou revalidadas pela Universidade Nacional de Assunção, e o registro habilitado pelo Ministério da Saúde Pública e Bem-Estar Social (Republica del Paraguay, 1980:24). Portanto, o controle do exercício profissional em saúde e em particular dos enfermeiros, está centralizado no Ministério da Saúde, a cargo do Departamento de Controle Profissional, que por sua vez encarrega a Direção dos Serviços Médicos do registro dos profissionais, o qual outorga a carteira de habilitação profissional (MSPyBS, 1986:1). O sistema de registro foi implantado em 1986 através da Resolução № 74 do Ministério da Saúde que determinou um período de seis meses para a inscrição de todos os profissionais existentes no país até aquela data; a inscrição de novos habilitados; e estabeleceu, em cinco anos, a validade dos registros. Para revalidação do registro, ou mesmo o registro inicial, não existem requisitos adicionais (exames de capacitação) além do diploma universitário (MSPyBS, 1986a:1-2). Para os profissionais formados no exterior, toda a documentação e título exigidos são examinados pela Universidade Nacional para a revalidação da titulação correspondente, e posterior registro nos Serviços Médicos do MSPyBS, não havendo impedimento Constitucional para o exercício profissional em saúde no país, exceto em relação ao nível técnico e auxiliar de saúde (MSPyBS, 1986:1-2 ; MSPyBS, 1986a:2 ; Republica del Paraguay, 1992:16-17).

Em que pese a outorga ao Ministério da Saúde da atribuição relativa à regulamentação do exercício profissional do enfermeiro (e de todos os outros profissionais de saúde); até a atualidade, não existe no país uma lei de exercício profissional para esta categoria. Em 1994, a "Asociación Paraguaya de Enfermeras", reconhecendo que a legislação da profissão se constitui numa necessidade diante da livre circulação de mão-de-obra prevista no Mercosul, elaborou o "Projeto de Legislación Laboral de la Enfermería Paraguaya" e entregou-o ao Poder Legislativo nesse mesmo ano, onde até hoje encontra-se para apreciação. Depara-se com esta mesma situação o Projeto de Lei que regulamenta o "Colegio de Enfermeras/os del Paraguay" e o "Codigo de Etica" (Asociación Paraguaya de Enfermeras, 1994:30). 
Em vigência, portanto, o Ministério da Saúde reconhece como categorias de enfermagem os enfermeiros, os técnicos e os auxiliares de enfermagem ${ }^{13}$. Como enfermeiro (ou "Licenciado en Enfermeria") o MSPyBS este profissional, cujo perfil é símil à definição elaborada pela "Asociación Paraguaya de Enfermeras" (em 1987 e em conjunto com os representantes do "Consejo Internacional de Enfermeras" e da Organização Mundial de Saúde), que conceituou enfermeira ${ }^{14}$ como ... "una persona que ha cursado enteramente enseñanza básica de enfermeria y está autorizada para exercer la enfermeria en su país. La enseñanza básica de enfermeria es un plan de estudios oficialmente reconocido que proporciona un núcleo amplio y sólido de conocimientos en ciencias de la conducta, biológicas y de la enfermeria para la practica general de esta última, el liderazgo dentro de la misma y enseñanza especializada avanzada o post-básica" (Asociación Paraguaya de Enfermeras, 1994:8). A enfermeira está, portanto, qualificada e autorizada para trabalhar na docência em enfermagem; na prevenção das doenças; no cuidado aos enfermos físicos e mentais, das pessoas impedidas de qualquer idade, em todos os contextos da assistência de saúde e do trabalho comunitário; como encarregada para ensinar a assistência de saúde; para participar plenamente como membro na equipe de assistência à saúde; para supervisionar e instruir as auxiliares ${ }^{15}$ de enfermagem na assistência à saúde; e para participar na pesquisa (Asociación Paraguaya de Enfermeras, 1994:8).

Atualmente, a forma de organização de interesses dos enfermeiros, no Paraguai, está representada somente pela "Asociación Paraguaya de Enfermeras", criada em 1952, com sede na Escola de Enfermagem do Instituto Andrés Barbero. Esta entidade está ligada ao Conselho Nacional de Saúde do MSPyBS, com o qual mantém relações que the garante a própria sobrevivência ${ }^{16}$. Vale dizer que os 35 anos de regime militar não permitiram a associação e/ou sindicalização livre dos funcionários nacionais do setor saúde, a não ser sob a tutela do Estado.

Segundo Arnau e Pierantoni (1995:141), apesar dos impedimentos legais e da lei do funcionário público (que também coibia as associações corporativas ou

\footnotetext{
${ }^{13}$ Titulares de certificados expedidos pelas instituições de ensino do Paraguai e reconhecidos pelo MSPyBS, cujo equivalentes estrangeiros são constitucionalmente impedidos para o exercício profissional no país (Asociación Paraguaya de Enfermeras, 1994:23-26). Em 1992, segundo o Censo (Republica del Paraguay, 1994:25-28), os técnocos e os auxiliares de enfermagem totalizavam respectivamente, 516 e 2.726 . Entretanto, entre estes existiam os "empíricos", além de outro grande contingente de atendentes de enfermagem no país, estimado em 5.000 em 1992 (Asociación Paraguaya de Enfermeras, 1994:33).

${ }^{14}$ No feminino, de acordo com o texto original.

${ }^{15}$ No feminino, conforme texto original.

${ }^{16}$ Conclusão nossa diante das informações (sobre o total de recursos, verba obtida através de eventos, quotas de associados, apoio financeiro e subordinação política e técnico ao MSPyBS ) obtidas na entrevista com a Presidente da Associação Paraguaia de Enfermeiras, Licenciada Juana Caceres de Gomes, em 02/04/96, na Escola de Enfermagem da UNA.
} 
sindicais), os profissionais se organizaram nas instituições de saúde, tornando-se, em alguns casos (particularmente no Hospital das Clínicas da UNA), focos de resistência ao regime de Stroessner, liderando estas associações em alguns momentos a mobilização em oposição ao governo autoritário. $\mathrm{Na}$ análise das autoras, após 1989, com o início do período de transição para a democracia, observa-se a tendência ao estabelecimento de associações por instituições (em hospitais públicos), por profissões (médicos, enfermeiros, bioquímicos) e a constituição da Federação dos Profissionais de Saúde. Observam também que, embora haja atualmente a liberdade de expressão e associação, ainda tem sido lenta a retirada dos obstáculos jurídicos à associação.

Assim, tanto os enfermeiros quanto os médicos ${ }^{17}$, vêm tentando criar os seus Colegiados, aguardando a sanção da Câmara dos Deputados para suas respectivas Leis de Colegiados, através das quais pretendem obter respaldo legal para regulamentação e controle do exercício profissional no país através da associação corporativa. Embora a nova Constituição garanta, em seu Artigo 42 do Capítulo VI da Saúde, que ... "Toda persona es libre de asociarse o agremiarse con fines lícitos, asi como nadie está obligado a pertenecer a determinada asociación. La forma de colegiación será reglamentada por Ley" ... (Republica del Paraguay, 1992:13), percebe-se a incoerência com o Código Sanitário ainda em vigência, o qual garante ao MSPyBS $\circ$ poder de regulamentação e controle do exercício das profissões de saúde no país. Sem dúvida, a atualização do Código Sanitário e a criação de leis que regulamentem - referido Artigo Constitucional constituem pontos importantes de estrangulamento na livre associação corporativa, ao mesmo tempo que representam uma ameaça de esvaziamento e enfraquecimento dos órgãos técnicos do MSPyBS.

\section{CONSIDERAÇÕES FINAIS}

O que se percebe em comum nas regulamentações da enfermagem no Cone Sul é que, apesar do não reconhecimento legal do exercício da enfermagem pelos "empíricos", ele ocorre na prática e representa a grande força de trabalho da equipe de enfermagem. Entretanto, os atendentes são objeto de preocupação, no sentido de sua escolarização e profissionalização, apenas no Brasil e na Argentina. Mesmo que a lei brasileira do exercício profissional, o projeto de lei argentina (que mais especificam as atribuições de acordo com as categorias de enfermagem) e ainda os projetos de lei uruguaia e paraguaia explicitem as atribuições exclusivas dos enfermeiros e os limites da prática dos

\footnotetext{
${ }^{17}$ Para esta categoria, a informação foi obtida durante entrevista dia 29/03/96 com Dra. Maria Cíntia Prieto Conti, representante do MSPyBS para os assuntos de saúde no Mercosul.
} 
técnicos e dos auxiliares, na realidade, os países convivem com a assistência de enfermagem prestada pelos atendentes e os auxiliares de enfermagem em todos os niveis de complexidade nos seus sistemas de saúde. A exclusividade das atribuiçőes dos enfermeiros é, portanto, utópica em relação à prestação dos cuidados de enfermagem no Cone Sul.

Em relação ao controle do exercício profissional, destacamos que, no Brasil, devido ao grande quantitativo dos recursos humanos de enfermagem e à complexidade da rede de instituições de saúde, os Conselhos Regionais não dão conta de um controle eficaz do exercício ilegal da enfermagem, mesmo considerando-se que é o único país do Mercosul que conta com um órgão (e sua rede de filiais) com autonomia e instrumento legal para o controle do exercício profissional das categorias de enfermagem. Embora disponha da legislação, a Argentina encontra-se na mesma situação do Uruguai e Paraguai (sem ainda legislação especifica), visto que seus respectivos Ministérios da Saúde centralizam o poder da outorga da licença e do controle do exercício profissional. Tendo em vista a estrutura disponivel nestes últimos países para o controle do exercício profissional, podemos afirmar que praticamente inexiste este controle, à exceção, em caso de denúncia do exercício ilegal.

Os colégios da Argentina, Uruguai e Paraguai, por sua vez, apesar da pretensão de regulamentar e controlar a prática da enfermagem nos seus paises, não dispõem, além dessas prerrogativas legais, de organização representativa nos estados, de infra-estrutura fisica, de recursos humanos e financeiros. O Colégio do Paraguai encontra-se em situação mais precáriasequer conta com sede própria, utilizando um espaço cedido no Instituto Andrés Barbero.

Vale lembrar que são estes os Colégios, além do COFEN, que, associados, constituem a Comissão Regional de Enfermagem do Mercosul (CREM) e esta, através da sua pretendida legalização junto às instituiçőes do Mercosul como órgão representativo da enfermagem na região, aspira, além do assessoramento técnico junto ao Grupo Mercado Comum, à responsabilidade pela regulamentação, autorização e controle do exercício profissional de todas as categorias de enfermagem no Mercosul. Sua atuação trataria não somente da mobilidade dos profissionais como também permearia todas as questōes inerentes à enfermagem, como formação, currículo, pós-graduação, política de recursos humanos, salários e empregos que obviamente têm implicações diretas com possiveis acordos, inclusive os de livre trânsito discente, docente e profissional.

A legitimação da CREM, como órgão oficial normativo e também na verdade fiscalizador, implica a discussão de sua capacidade política e gerencial do exercício pretendido e da necessidade de representação das diversas áreas como as instituições de saúde e de educação dos países envolvidos. 


\section{REFERÊNCIAS BIBLIOGRÁFICAS}

1. ABRAMZÓN, M. C. 1995. "Argentina: Situação do Recursos Humanos em Saúde". In: Recursos Humanos em Saúde no Mercosul. Rio de Janeiro. OPS/OMS/FIOCRUZ.

2. ARNAU, A. ; PIERANTONI, C. 1995. "Paraguai: Situação da Formação e Mercado de Trabalho na área de Saúde". In: Recursos Humanos em Saúde no Mercosul. Rio de Janeiro. OPS/FIOCRUZ.

3. ASOCIACIÓN PARAGUAYA DE ENFERMERAS. 1994. Situación de Enfermería en Paraguay. Comité Mercosul. APE. Asunción. (mímeo).

4. CAMPOS, F. ; BRITO, P. ; RÍGOLE, F. 1995. "O Campo dos Recursos Humanos para a Saúde no Mercosul". IN: Recursos Humanos em Saúde no Mercosul. OPS. Rio de Janeiro. Fiocruz.

5. CLEMENTE, V. 1994. "Situación de Enfermeria en el Uruguar". Conferencia en la XVI Jornada Nacional del Colegio de Enfermeras del Uruguay y $1^{\circ}$ Encuentro Regional Enfermeria-Mercosul. Montevidéu. 13 y 14 de octubre. ( mímeo).

6. COFEN. 1990. Documentos Básicos do Cofen. Rio de janeiro. Cofen. V.11.

7. COFEN. 1994. Registro e Cadastro. População de Profissionais de Enfermagem Cadastrados até 31/12/94. Rio de Janeiro.

8. COLEGIO DE ENFERMERAS DEL URUGUAY. 1992. Estatuto del Colegio de Enfermeras del Uruguay. CEDU. Montevidéu.

9. COLEGIO DE ENFERMERAS DEL URUGUAY. 1995. Proyecto de Ley Nacional de Enfermeria. Montevidéu. (mímeo).

10. IBGE. 1992. Pesquisa Assistência Médica Sanitária. Rio de Janeiro. IBGE.

11. INSTITUTO NACIONAL DE ENFERMERIA ; COLEGIO DE ENFERMERAS DEL URUGUAY. 1995. $1^{\circ}$ Censo Nacional de Enfermería Profesional. Noviembre-Deciembre 1993. Montevidéu. Cedu.

12. MSPyBS. 1986. Resolución $\mathrm{N}^{\circ} 17$. Regulamentación del Exercicio de las Proesiones Tecnicas y Auxiliares en Ciencias de la Salud. Asunción. 31 de Enero.

13. MSPyBS. 1986a. Resolución $\mathrm{N}^{2}$ 74. Sistema de Registro de Professionales en Ciencias de la Salud. Asunción. 2 de Marzo.

14. MUÑOZ, S. E. ; MALVÁREZ, S. M. ; DAVINI, M. C. ; HEREDI, A. M. 1995. Desarrollo de Enfermeria en Argentina 1985-1995 - Análisis de Situación y líneas de Trabajo. Buenos Aires. OPS/OMS.

15. OPS/MINISTERIO DE SALUD Y ACCIÓN SOCIAL DE LA NACIÓN/ SECRETARIAS DE SALUD DE LAS PROVINCIAS. 1994. Estudios de

R. Bras. Enferm. Brasília, v. 51, n. 1, p. 123-138, jan./mar., 1998 
Actualización del Recurso Humano de Enfermería. Buenos Aires. OPS.

16. PITAMIGLIO, C. 1995. Regimen Legal de las Profesiones de Salud en Uruguay. Capitulo III. Recursos Humanos. Montevidéu. MSP.

17. PRESIDENCIA DE LA REPUBLICA. 1991. Lei N²4.004. 23 de Octubre. Buenos Aires.

18. REPUBLICA DEL PARAGUAY. 1936. Decreto Ley $N^{\circ} 2001$. Ley Orgánica de Salud Pública. Asunción. 15 de Junio.

19. REPUBLICA DEL PARAGUAY. 1958. Decreto No 35.094. Requisitos para el Ejercício de la Profesion de Enfermería. Asunción. 25 de Julio.

20. REPUBLICA DEL PARAGUAY. 1963. Decreto $N^{\circ}$ 29.107. Autoriza al Ministerio de Salud Publica y Bienestar Social a realizar gestiones y firmar convenio para incorporar a la Universidad Nacional de Asunción al Instituto de Enseñanza Dr. Andrés Barbero. Asunción. 29 de Mayo.

21. RePUblicA DEL PARAguAy. 1980. Código Sanitario Nacional. Asunción.

22. REPUBLICA DEL PARAGUAY. 1992. Constitución Nacional. Asunción.

23. REPUBLICA DEL PARAGUAY.1994. Censo Nacional de Poblacion y Viviendas de 1992. Secretaria Tecnica de Planificación. Direción General de Estadísticas, Encuestas y Censos. Asunción. Julio.

24. REPUBLICA ORIENTAL DEL URUGUAY. 1934. Ley Organica No9.202 de 12/01/34. Montevidéu.

25. REPUBLICA ORIENTAL DEL URUGUAY. 1967. Constituición de la Republica Oriental del Uruguay. Montevidéu. Fundación Cultura Universitaria. 1995.

26. RíGOLE, F. 1991. Recursos Humanos en el Sector Salud del Uruguay. Montevidéu (mímeo).

27. RÍGOLE, F.; SUGO, M.; SERRA, J. 1995. "Formação e Mercado de Trabalho de Algumas Categorias Profissionais de Saúde no Uruguai". IN: Recursos Humanos para a Saúde no Mercosul. OPS. Rio de Janeiro. Fiocruz. 